\title{
IMPRESSION CYTOLOGY OF TARSAL CONJUNCTIVA IN LONG-STANDING OCULAR PROSTHESIS WEARERS: CASE REPORTS
}

\author{
BARIAH MOHD-ALI*, MOHD NORHAFIZUN MOHD-SAMAN
}

Program of Optometry and Vision Sciences and School of Community Health, Faculty of Health Sciences, Universiti Kebangsaan Malaysia, Jalan Raja Muda Abdul Aziz 50300 Kuala Lumpur. Malaysia. Email: bariah@ukm.edu.my

Received: 21 March 2018, Revised and Accepted: 30 April 2018

\section{ABSTRACT}

Impression cytology is a simple technique that can be used to identify patients who are at risk of developing ocular surface disorders. Giant papillary conjunctivitis (GPC) is an allergic reaction affecting the ocular tarsal conjunctiva predominantly associated with contact lens wear and also observed in anophthalmic patients wearing ocular prosthesis. Here, we described the outcomes of using impression cytology technique in diagnosing GPC in two long-standing ocular prosthesis wearers.

Keywords: Giant papillary conjunctivitis, Ocular prosthesis, Impression cytology.

(C) 2018 The Authors. Published by Innovare Academic Sciences Pvt Ltd. This is an open access article under the CC BY license (http://creativecommons. org/licenses/by/4. 0/) DOI: http://dx.doi.org/10.22159/ajpcr.2018.v11i8.26107

\section{INTRODUCTION}

Impression cytology is a non-invasive technique, easy to perform, and yields reliable information with minimal discomfort to the patient, making it a valuable tool in diagnosing ocular surface disorders [1]. The technique uses either acetate cellulose filter paper or membrane device to remove superficial layers of the ocular surface epithelium with the aid of topical ocular anesthetic. The cells thus removed are subjected to histological, immune-histological, or molecular analysis. The technique was first described by Egbert et al. [2] to investigate the conjunctival goblet cells. Since then, the method has been used by many investigators to evaluate ocular surface disorders and to monitor the impact of contact lens wear and ocular prosthesis on ocular surface plus monitoring tolerance and efficacy of therapeutic interventions $[3,4]$.

Giant papillary conjunctivitis (GPC) is a conjunctivitis that accompanies proliferative changes in the tarsal conjunctiva induced by mechanical irritations such as contact lenses, ocular prosthesis, and surgical sutures [5]. The condition is characterized by a series of symptoms associated with inflammation and changes in the tarsal conjunctiva that include itching, tearing, excessive ocular discomfort, and mucus production [6,7]. The papillae are $1 \mathrm{~mm}$ or more in diameter, have central blood vessel, and are typically seen on the upper tarsal conjunctiva [5]. The tips of the papillae commonly stain with fluorescein and mucus are found in between them. GPC associated with ocular prosthesis wear was initially described by Srinivasan et al. [8]. The papillary changes in these patients were not always symptomatic, and the increase in mucin discharge was associated with the increased production of epithelial mucin rather than goblet cell mucin. Despite the presence of disabling and prominent symptoms, this inflammatory condition is less studied [9]. This article reports cytological features of tarsal conjunctiva in 2 anophthalmic retinoblastoma patients who have been wearing ocular prosthesis for more than 10 years. Both patients used a similar technique to clean their prosthesis but experienced different symptoms. The symptoms and findings from slit lamp investigation and impression cytology are discussed below. Informed consent was obtained from the institutional human ethics committee and patients. Impression cytology technique was done on both patients using either acetate cellulose filter paper to remove superficial layers of the ocular surface with the aid of topical ocular anesthetic $(0.5 \%$ proparacaine hydrochloride). The specimens were evaluated under light microscope, and several features are universally evaluated including the quality of the epithelial cells, the density, shape, and periodic acid-Schiff intensity of goblet cells present and the presence of non-epithelial cells, i.e., inflammatory cells and microorganisms.

\section{CASE REPORTS}

Case 1

A 19-year-old Malay female presented with history wearing ocular prosthesis for 15 years. Her right eye was enucleated at $1 \frac{1}{2}$ years old due to retinoblastoma and was fitted with ocular prosthesis 3 years later. She is currently wearing a custom-made ocular prosthesis which was fitted 4 years ago. Follow-up examination was done frequently by the ophthalmologist, and the prosthetic eye was cleaned monthly using tap water. The patient reported that she had experienced symptoms of itching, irritation, discharge, and swelling of upper lid on previous occasions and was prescribed with Maxitrol ${ }^{\circledR}$ (dexamethasone $0.1 \%$, neomycin sulfate, polymyxin B sulfate) to reduce the symptoms. There were slight redness and swelling of the upper lid on the day of her examination but with no pain or discharge. Using slit-lamp biomicroscopy, the appearance (roughness and redness) of the upper tarsal conjunctiva was graded following Institute of Eye Research (IER) grading scale of contact lens complications [10]. In this case, both redness and roughness were graded as 4.0 which indicates the appearance of GPC on her upper tarsus. There were no indications of GPC on her left eye. The redness and roughness of the upper tarsal conjunctiva of her left eye were graded as 1.0 indicating healthy appearance.

Impression cytology revealed enlargement of cells with inflammatory infiltrates. Honeycomb pattern with larger and more polygonal shape of epithelial cells was also noted. The nuclear-to-cytoplasmic ratio was 1:3 (Table 1), and mucous strands were present. Specimens from the contralateral eye showed uniform high-density epithelial cells morphology with the presence of goblet cells. The nuclear-tocytoplasmic ratio was 1:2 with no mucous strand.

Case 2

A 16-year-old Indian male presented with a history of wearing ocular prosthesis for 13 years. He underwent enucleation of his right eye at the age of 3 due to retinoblastoma and was fitted with ocular prosthesis immediately after recovering from surgery. He is currently wearing a custom-made ocular prosthesis that was fitted 5 years ago and used tap 
Table 1: Cytology features of cytology impression

\begin{tabular}{|c|c|c|c|c|c|}
\hline \multirow[t]{2}{*}{ Case } & \multirow[t]{2}{*}{ Goblet cells } & \multirow[t]{2}{*}{ Epithelial cells } & \multicolumn{2}{|l|}{$\mathrm{N} / \mathrm{C}$ ratio } & \multirow[t]{2}{*}{ Mucous strand } \\
\hline & & & Contralateral & Anophthalmic & \\
\hline 1 & Absent & $\begin{array}{l}\text { Larger and polygonal Honeycomb pattern with inflammatory } \\
\text { infiltrates }\end{array}$ & $1: 2$ & $1: 3$ & Noticed \\
\hline 2 & Absent & Mild enlargement Non-uniform shape & 1.2 & $1: 3$ & Noticed \\
\hline
\end{tabular}

N/C: Nuclear to cytoplasmic

water to clean the prosthesis daily. He attended his follow-up examination with the ophthalmologist regularly and had his prosthetic polished frequently by the Ocularist. The patient adapted well to the ocular prosthesis and had no problems wearing it every day. Following the IER grading scale, both roughness and redness of the upper tarsal conjunctiva were graded as 1.5 , which indicates a near normal appearance of tarsal conjunctiva. The roughness and redness of the left eye were graded as 1.0.

In this case, there was less density of epithelial cells without the presence of goblet cells and mild enlargement of the epithelial cells on the right eye. Nevertheless, the nuclear-to-cytoplasmic ratio was 1:3 (Table 1) and mucous strands presence were noticed. A uniform highdensity epithelial cell morphology with the presence of goblet cells was noted on the contralateral eye. The nuclear-to-cytoplasmic ratio was 1:2.

\section{DISCUSSION}

GPC was first reported as an allergic reaction affecting the upper tarsal conjunctiva in patients wearing contact lenses [11]. The condition can be seen with all types of contact lenses including silicone hydrogels [12]. According to Donshik [13], GPC is more common in reusable soft contact lens (85\%) than RGP wearers (15\%) and may develop after years of successful contact lens wear. Its etiology is known to be multifactorial, being a combination of an immune response (immediate type I hypersensitivity and delayed Type 4 hypersensitivity) to antigenic proteins on the contact lens surface and mechanical effects of the lens edge and surface causing trauma to the conjunctiva.

It is well known that long-term prosthetic wear causes several abnormalities in the orbit, eyelid, and conjunctiva such as meibomian gland dysfunction, lower eyelid retraction, and GPC [14]. However, the appearance of GPC in prosthetic wearers was reported in symptomatic patients only $[15,16]$. In this article, we reported two cases involving patients with a history of retinoblastoma. Retinoblastoma refers to a type of cancer that is caused by uncontrolled growth in precursor cells usually known as blasts, and it is more frequent in children [17]. Both patients have been wearing ocular prosthesis for more than 10 years and had regular eye examinations with the ophthalmologist and ocularist, but only one of them (case 1) reported symptoms of itching, irritation, discharge, and swelling lid. Interestingly, specimens from both anophthalmic sockets showed cytological changes including enlargement of the epithelial cells and the increment of nuclear-tocytoplasm ratio compared with the control eyes. Goblet cells were absent, and mucous strand was also noticed in both cases. All of these changes indicate the development of conjunctival squamous metaplasia $[15,16]$. The squamous metaplasia is referred to pathologic transition of normal non-keratinized, stratified epithelial cells to nonsecretory, keratinized epithelial cells. The conjunctival changes were graded as follows: Stage 0 , normal goblet cell density with an $\mathrm{N} / \mathrm{C}$ ratio $1 / 1$; stage 1 , early loss of goblet cells without keratinization with an N/C ratio $1 / 2$ to $1 / 3$; stage 2 , total loss of goblet cells without keratinization and all epithelial cells moderately enlarged with an N/C ratio 1/4; stage 3 (mild keratinization), all epithelial cells markedly squamoid with an $\mathrm{N} / \mathrm{C}$ ratio 1/6; stage 4 (moderate keratinization), more densely packed keratin filament, pyknotic nuclei with an $\mathrm{N} / \mathrm{C}$ ratio $1 / 8$; and stage 5 (advanced keratinization), shrunken cytoplasm [15].

In case 1 , the presence of honeycomb pattern and inflammatory infiltrates indicates the higher degree of inflammation. However, based on nuclear-to-cytoplasm ratio, the ratio was still low (1:3) compared with the inflammatory degree. It is possible that the changes observed were due to Maxitrol ${ }^{\circledR}$ used by the patient. Kim et al. [18] suggested that all medications used by the prosthesis wearers and particularly the topical steroids could cause low-grade conjunctival cytology changes. In case 2, the patient was asymptomatic but showed similar cytological changes as in case 1 . This indicates that there are changes happening at cellular level even when the appearance of the tarsal conjunctiva (redness and roughness) looked normal. It is possible that GPC associated with ocular prosthetic wear is an allergic disease of the eye with increased number of inflammatory cells in the conjunctiva, which directly linked to the chronic exposure of foreign bodies such as continuous use of ocular prosthesis $[3,18]$.

\section{CONCLUSION}

The cases highlight the existence of GPC in asymptomatic ocular prosthetic wearers. Even though the eye appears normal, practitioners must be alert to the possibility of the development of GPC in ocular prosthetic wearers. Impression cytology can be used to identify patients who are at risk of developing GPC so that early intervention can be prescribed to them. The technique was proven to be fast and safe and should be considered by eye care practitioners for the diagnosis of the ocular surface conditions.

\section{CONFLICTS OF INTEREST}

The authors do not have any conflict of interest to declare.

\section{AUTHORS' CONTRIBUTION}

Both authors contributed equally in the data collection and manuscript preparation.

\section{ACKNOWLEDGMENT}

The authors acknowledge the assistance of Associate Prof Dr. Yanti Rosli from Biomedical Science program and Ms. Asmah Ahmad from Optometry and Vision Science program, in this study.

\section{REFERENCES}

1. Singh R, Joseph A, Umapathy T, Tint NL, Dua HS. Impression cytology of the ocular surface. Br J Ophthalmol 2005;89:1655-9.

2. Egbert PR, Lauber S, Maurice DM. A simple conjunctival biopsy. Am J Ophthal 1977;84:798-801.

3. Chang WJ, Tse DT, Rosa RH, Huang A, Johnson TE, Schiffman J. Conjunctival cytology features of giant papillary conjunctivitis associated with ocular prostheses. Ophthal Plast Reconstr Surg 2005;21:39-45.

4. Doughty MJ. Contact lens wear and the development of squamous metaplasia of the surface cells of the conjunctiva. Eye Contact Lens 2011;37:274-81.

5. Takamura E, Uchio E, Ebihara N, Ohno S, Ohashi Y, Okamoto S, et al. Japanese guidelines for allergic conjunctival disease 2017. Allergol Int 2017;66:220-9.

6. Bielory L. Allergic and immunologic disorders of the eye. Part II: Ocular allergy. J Allergy Clin Immunol 2000;106:1019-32.

7. Bozkurt B, Akyurek N, Irkec M, Akyurek N, Irkec M, Erdener U, et al. Immunohistochemical findings in prosthesis-associated giant papillary conjunctivitis. Clin Exp Ophthal 2007;35:535-40.

8. Srinivasan BD, Jakobiec FA, Iamoto T, De Voe AG. Giant papillary conjunctivitis with ocular prostheses. Arch Ophthalmol 1979;97:892-5. 
9. Satyam SM, Adiga S, Chogtu B, Bairy KL, Pirasantahn R, Vaishnav RL. Effect of fucithalmic and sofinox eye drops on experimental allergic conjunctivitis in rats. Int J Pharm Pharm Sci 2014;6:458-60.

10. Ishak B, Mohd-Ali B, Mohidin N. Grading of tarsal conjunctiva of young adults in Malaysia. Clin Exp Optom 2011;94:458-63.

11. Spring TF. Reaction to hydrophilic lenses. Med J Aust 1974;1:499-500.

12. Yeniad B, Yakubi SA, Bilgin LK, Adam YS, Gözüm N. Effect of 30day continuous wear of silicone hydrogel contact lenses on corneal thickness. Eye Contact Lens 2004;30:6-9.

13. Donshik PC. Extended wear contact lenses. Ophthalmol Clin N Am 2003;16:305-9.
14. Sun YJ, Sang YL, Jin SY. Meibomian gland dysfunction in longstanding prosthetic eye wearers. Br J Ophthalmol 2013;97:398-402.

15. Tseng SC. Staging of conjunctival squamous metaplasia by impression cytology. Ophthalmology 1985;92:728-33.

16. McKelvie, P. Ocular surface impression cytology. Adv Anat Pathol 2003;10:328-37.

17. Gupta M, Dahiya I, Marwaha RK, Dureja H. Therapies in cancer treatment: An overview. Int J Pharm Pharm Sci 2015;7:1-9.

18. Kim JH, Lee MJ, Choung H, Kim NJ, Hwang SW, Sung MS, et al. Cytologic features in anophthalmic patients wearing an ocular prosthesis. Ophthal Plastic Reconstr Surg 2008;24:290-5. 